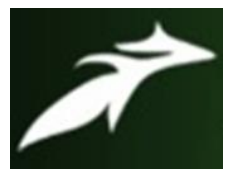

Smit Smarak Mishra et al, International Journal of Advances in Agricultural Science and Technology,

Vol.8 Issue.9, September-2021, pg. 83-91

ISSN: 2348-1358

Impact Factor: 6.057

NAAS Rating: 3.77

\title{
IMPACT OF BIJU KRUSHAK KALYAN YOJANA (BKKY) IN ANGUL DISTRICT OF ODISHA
}

\author{
Smit Smarak Mishra ${ }^{1}$; Dipak Kumar Bose ${ }^{2}$; Jahanara ${ }^{3}$ \\ ${ }^{1}$ M.Sc. Ag. (Agricultural Extension and Communication), SHUATS (Prayagraj) \\ ${ }^{2}$ Associate Professor, Department of Agriculture Extension and Communication, SHUATS (Prayagraj) \\ ${ }^{3}$ Head, Department of Agriculture Extension and Communication, SHUATS (Prayagraj) \\ Author's e-mail: smitsmarak@gmail.com \\ DOI: 10.47856/ijaast.2021.v08i9.010
}

\begin{abstract}
Villages and its farmers are the base of Odisha. But, when farmers suffer from ailments, they have to pay heavy economic, social and emotional price. Financial hazard and health related expenses led the farmer to suffer in poverty. Whereas, Biju Krushak Kalyan Yojana (BKKY) brought as a solution to farmers for their health security. The study was conducted in Angul district of Odisha under ex-post facto research design. 120 respondents from 10 villages of Angul block in Angul district of Odisha was selected for the study. Primary data were collected from the respondents with the help of pre-tested semi-structured interview schedule through personal interview. Data collected were subjected to statistical analysis and the identified that majority of the respondents were middle aged, illiterate, earns medium level of annual income, with medium level of mass media exposure and extension contact. Further added that, respondents reported positive impact on BKKY and socio-economic characteristics like education, income, mass media exposure and extension contact has positive and significant association with the impact of BKKY among the farmers. It was suggested to create awareness among farmers on benefits of BKKY, providing quality health consultations, proper knowledge at timely manner.
\end{abstract}

Keywords: Health insurance, Farmers, Odisha, BKKY, Angul district, Impact

\section{Introduction}

Odisha lives in its Villages and farmers are its backbone. They toil hard to feed the nation. They suffer in silence and when they are affected by ailments and diseases, pay heavy economic, social and emotional price. The most important and major cause of our farmers falling to poverty trap is the financial hazards and deprivation that health related expenses bring to them. 


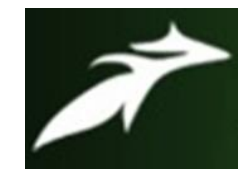

Smit Smarak Mishra et al, International Journal of Advances in Agricultural Science and Technology, Vol.8 Issue.9, September-2021, pg. 83-91

ISSN: 2348-1358

Impact Factor: 6.057

NAAS Rating: 3.77

Biju Krushak Kalyan Yojana is brought in as a tribute to the Farmers and their families to provide them health security. It is an earnest effort to provide them financial support through health and accident insurance as a part of the commitment of the welfare state. Rural

Odisha houses $83 \%$ of the total population of the state. One of the major insecurities for rural populace and farmers is absence of health cover for such farmers and their family members. Insecurity relating to absence of health cover, heavy expenditure on medical care and hospitalization and recourse to inadequate and incompetent treatment is not only a social and psychological burden borne by these populace but there are significant economic costs resulting from loss of earning and progressive deterioration of health. Thus, with a view to providing health insurance cover to farmers in the Rural Odisha and their families, the Government of Odisha has announced the "Biju Krushak Kalyan Yojana".

A number of studies have revealed that risk owing to low level of health security is endemic for Farmers and their family members, especially those in unorganized sector. The vulnerability of these Farmers and their family members increases when they have to pay out of pocket for their medical care with no subsidy or support. On the one hand, such a farm family does not have the financial resources to bear the cost of medical treatment; on the other, the public owned health infrastructure is unable to cope up with the demand. Large number of persons borrows money or sells assets to pay for treatment in hospitals. Thus, Health Insurance can be a way of overcoming financial handicaps, improving access to quality medical care and providing financial protection against high medical expenses.

The "Biju Krushak Kalyan Yojana" announced by the Government of Odisha attempts to address such issues. For effective operation of the scheme, partnership is envisaged between the Insurance Company, public and the private sector hospitals and the State agencies. State Government/Nodal Agency will assist the Insurance Company in networking with the Government/Private hospitals, fixing of treatment protocol and costs, treatment authorization, so 


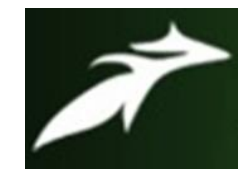

Smit Smarak Mishra et al, International Journal of Advances in Agricultural Science and Technology, Vol.8 Issue.9, September-2021, pg. 83-91

ISSN: 2348-1358

Impact Factor: 6.057

NAAS Rating: 3.77

that the cost of administering the scheme is kept at the lowest, while making full use of the resources available in the Government/Private health systems.

Similar studies like, Acharya et al. (2012) reported that health insurance reduced out-ofpocket health expenses; the effect for the poorest was weaker than for the near poor. Gill and Shahi (2012) identified that lack of awareness is one of the significant causes among beneficiaries behind spending from their own pocket at the time of illness.Rajasekhar and Manjula (2012) revealed that State government has sought to initiate and promote health insurance schemes that target the disadvantaged sections of society. Kiran and Chetan (2013) commented that the main objective of a health care system is to maintain or improve the health status of the population.

Meanwhile, Somil nagpal (2013) found very positive efforts of government of India and aimed at improving the availability of and access to health services, particularly for the poor and vulnerable groups in the country. Bandyopadhyay and Sen K (2017) argued that market failure conditions of this insurance model will continue to perpetuate losses for not only the state, but also for insurance companies, unless they adjust on a continuous basis for profit by raising the premium rate. This will further deplete state budgets for health care affecting the viability of the scheme in the long run.

Eventually, Panda (2019) reported the problems in insurance were lack of awareness, no proper enrolment procedure, no cooperative hospital staff, limited assured money sanctioned per day, only inpatient care services, an unhygienic atmosphere in the hospital, long distance to the empanelled hospital and exploitation among health service providers. Awareness may be created among insured. The behaviour of healthcare providers may be turned friendly. Immediate attention may be provided by help desk counters to the beneficiaries. The sum assured amount may be increased. The detailed receipt of hospital expenditure may be supplied to the insured at the time of discharge. 


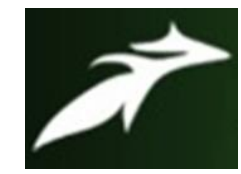

Smit Smarak Mishra et al, International Journal of Advances in Agricultural Science and Technology, Vol.8 Issue.9, September-2021, pg. 83-91

ISSN: 2348-1358

Impact Factor: 6.057

NAAS Rating: 3.77

\section{Statement of the problem}

The scheme was implemented through the Director of Agriculture and Food Production, Government of Odisha. The scheme aims to improve the access of identified farmer families to quality medical care for treatment of diseases involving hospitalisation through a designated network of healthcare providers. This scheme is trying to support more than 60 lakh farmers The topic is selected with the particular area of research is because the project was started in the Angul district of Odisha firstly and the project is active till now hence farmers are facing financial problems they cannot afford medical expenditure so this research is to find out how far the project have reached to improve the farmers welfare with providing health insurance. In this context, the following objectives were formulated;

1. To assess the socio-economic profile of the beneficiaries and non-beneficiaries.

2. To find out the knowledge and attitude of the respondents towards Biju Krushak Kalyan Yojana.

3. To determine the impact of Biju Krushak Kalyan Yojana on its beneficiaries and nonbeneficiaries.

4. To find out the association between selected independent variables with dependent variables.

5. To identify the constraints faced by the respondents to avail the services and seek their suggestion for better services of Biju Krushak Kalyan Yojana.

\section{Methodology}

Ex-post facto research design is adopted for the study. Angul district is purposively selected since BKKY was first implemented in this District and there are adequate numbers of beneficiaries present according to the pilot survey in comparison to other districts. Out of 8 blocks in Angul district of Odisha, Angul block has been selected since it has maximum area covered by BKKY. From 96 villages in Angul block, 10 villages were selected based on random 


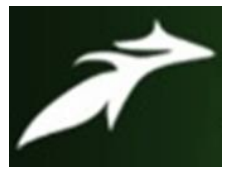

Smit Smarak Mishra et al, International Journal of Advances in Agricultural Science and Technology, Vol.8 Issue.9, September-2021, pg. 83-91

ISSN: 2348-1358 Impact Factor: 6.057

NAAS Rating: 3.77

sampling technique. The selected villages were Ambapal, Natada, Kuio, Jamunali, Kukudanga, Raipur, Tentoi, Suleimal, Talataila and Kumanda. From the selected ten villages of Angul block, 12 respondents were selected from each village. Thus, constitutes the 120 respondents for the study. Primary data were gathered with the help of pre-tested interview schedule from the respondents and secondary data from previous studies, literatures. The data gathered were subjected to statistical analysis and the results were presented.

\section{Results and Discussion}

The socio-economic profile of the respondents were studied under various characteristics and the results were presented under table.1.

Table.1. Socio-economic profile of the respondents $(n=120)$

\begin{tabular}{|c|c|c|c|c|}
\hline S. No. & Characteristics & Category & Frequency & Percentage \\
\hline \multirow[t]{3}{*}{1} & \multirow[t]{3}{*}{ Age (in years) } & Young $(<35)$ & 12 & 10.00 \\
\hline & & Middle(36-55) & 81 & 67.50 \\
\hline & & Old $(>55)$ & 27 & 22.50 \\
\hline \multirow[t]{6}{*}{2} & \multirow[t]{6}{*}{ Education } & Illiterate & 28 & 23.30 \\
\hline & & Primary education & 22 & 18.30 \\
\hline & & Junior high school education & 24 & 20.00 \\
\hline & & High school & 16 & 13.33 \\
\hline & & Higher secondary & 24 & 20.00 \\
\hline & & Graduate and above & 6 & 5.00 \\
\hline \multirow[t]{3}{*}{3} & \multirow[t]{3}{*}{ Annual Income } & Low & 45 & 37.50 \\
\hline & & Medium & 54 & 45.00 \\
\hline & & High & 21 & 17.50 \\
\hline \multirow[t]{4}{*}{4} & \multirow[t]{4}{*}{ Land holding } & Below 1 acre & 26 & 21.70 \\
\hline & & $1-2$ acre & 56 & 46.60 \\
\hline & & $2-3$ acre & 26 & 21.70 \\
\hline & & Above 3 acre & 12 & 10.00 \\
\hline \multirow[t]{2}{*}{5} & \multirow[t]{2}{*}{ Family size } & Small & 70 & 58.33 \\
\hline & & Medium & 34 & 28.33 \\
\hline
\end{tabular}




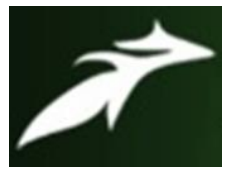

Smit Smarak Mishra et al, International Journal of Advances in Agricultural Science and Technology, Vol.8 Issue.9, September-2021, pg. 83-91

ISSN: 2348-1358

Impact Factor: 6.057

NAAS Rating: 3.77

\begin{tabular}{|c|c|c|c|c|}
\hline & & Large & 16 & 13.33 \\
\hline \multirow[t]{2}{*}{6} & \multirow[t]{2}{*}{ Family type } & Nuclear Family & 104 & 86.67 \\
\hline & & Joint Family & 16 & 13.33 \\
\hline \multirow[t]{3}{*}{7} & \multirow[t]{3}{*}{ Farming experience } & Less than 3 years & 12 & 10.00 \\
\hline & & $3-5$ years & 60 & 50.00 \\
\hline & & More than 5 years & 48 & 40.00 \\
\hline \multirow[t]{3}{*}{8} & \multirow[t]{3}{*}{ Mass media exposure } & Low & 21 & 17.50 \\
\hline & & Medium & 62 & 51.67 \\
\hline & & High & 37 & 30.83 \\
\hline \multirow[t]{3}{*}{9} & \multirow[t]{3}{*}{ Extension contact } & Low & 16 & 13.33 \\
\hline & & Medium & 71 & 59.17 \\
\hline & & High & 33 & 27.50 \\
\hline
\end{tabular}

From table.1, it can be interpreted that higher percentage of the respondents were middle aged $(67.50 \%)$, followed by old age $(22.50 \%)$ and young age (10\%). Majority of the respondents were illiterate $(23.30 \%)$, followed by junior high school education (20\%) and higher secondary (20\%), primary education (18.30\%), high school (13.33\%) and only 5 per cent of the respondents were graduate. Nearly half of the respondents earns medium level of annual income (45\%), followed by low (37.50\%) and high (17.50\%) level of annual income. Nearly half of the respondents possessed 1-2 acres (46.60\%), followed by an equal proportion of respondents possessed land holding of below 1 acre and 2-3 acre (21.70\%) and only 10 per cent of the respondents had land holding of above 3 acres.

More than half of the respondents had small family size (58.33\%), followed by medium size family (28.33\%) and big size family (13.33\%). Majority of the respondents reported nuclear family $(86.67 \%)$ followed by 13.33 per cent of respondents had joint family. Half of the respondents had 3-5 years of farming experience (50\%), followed by 40 per cent of respondents had more than 5 years of experience and only 10 per cent of the respondents had less than 3 years of experience. More than half of the respondents (51.67\%) had medium level of mass media exposure, followed by high (30.83\%) and low (17.50\%) level of mass media exposure. 


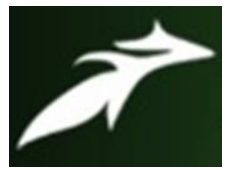

Smit Smarak Mishra et al, International Journal of Advances in Agricultural Science and Technology, Vol.8 Issue.9, September-2021, pg. 83-91

ISSN: 2348-1358

Impact Factor: 6.057

NAAS Rating: 3.77

Nearly two-third of the respondents had medium level of extension contact $(59.17 \%)$, followed by high $(27.50 \%)$ and low level $(13.33 \%)$ of extension contact.

Table.2. Distribution of respondents according to the impact of BKKY

$(\mathbf{n}=\mathbf{1 2 0})$

\begin{tabular}{|c|c|c|c|}
\hline S. No. & Category & Frequency & Per cent \\
\hline 1 & Positive impact & 93 & 77.50 \\
\hline 2 & Negative impact & 27 & 22.50 \\
\hline \multicolumn{2}{|r|}{ Total } & 120 & 100.00 \\
\hline
\end{tabular}

From table.2, indicates that more than two-third of the respondents had positive impact on BKKY (77.50\%) and some of them had negative impact on BKKY (22.50\%).

Table.3. Association between the independent variables and impact of BKKY among the farmers

\begin{tabular}{|c|l|c|c|c|c|}
\hline $\begin{array}{c}\text { S. } \\
\text { No. }\end{array}$ & \multicolumn{1}{|c|}{ Characteristics } & 'r' value & $\begin{array}{c}\text { Regression } \\
\text { co-efficient }\end{array}$ & $\begin{array}{c}\text { Standard } \\
\text { error }\end{array}$ & t-value \\
\hline $\mathrm{X}_{1}$ & Age & -0.367 & -0.677 & 0.258 & 0.459 \\
\hline $\mathrm{X}_{2}$ & Education & $0.101^{* *}$ & $2.519^{*}$ & 1.374 & $0.073^{*}$ \\
\hline $\mathrm{X}_{3}$ & Income & $0.035^{*}$ & $0.450^{*}$ & 3.465 & $0.056^{*}$ \\
\hline $\mathrm{X}_{4}$ & Land holding & 0.690 & 0.110 & 1.429 & 0.939 \\
\hline $\mathrm{X}_{5}$ & Farming experience & 0.415 & 6.995 & 4.367 & 0.689 \\
\hline $\mathrm{X}_{6}$ & Mass media exposure & $0.010^{*}$ & $-2.965^{*}$ & 1.184 & $0.016^{*}$ \\
\hline $\mathrm{X}_{7}$ & Extension contact & $0.038^{*}$ & $-4.072^{*}$ & 1.637 & $0.017^{*}$ \\
\hline
\end{tabular}

$\mathrm{R}^{2}=0.51$

$\mathrm{F}=3.489$

$\mathrm{a}=151.677$

NS $=$ Not Significant $; *=$ Significant at $5 \%, * *=$ Significant at $10 \%$. 


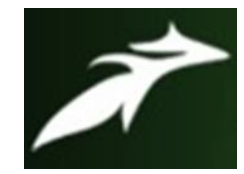

Smit Smarak Mishra et al, International Journal of Advances in Agricultural Science and Technology, Vol.8 Issue.9, September-2021, pg. 83-91

ISSN: 2348-1358

Impact Factor: 6.057

NAAS Rating: 3.77

From table.3, it can be understood that socio-economic characteristics like education, income, mass media exposure and extension contact has positive and significant association with the impact of BKKY among the farmers. Whereas, age of the respondents had negative and nonsignificant association with the impact of BKKY among the respondents. Meanwhile, farming experience and land holding of respondents had non-significant association with the impact of BKKY among the farmers.

\section{Conclusion}

From the study, it can be concluded that majority of the respondents were middle aged illiterate, earns medium level of annual income, possessed 1-2 acres with small family size and nuclear family. Meanwhile, they had 3-5 years of farming experience, medium level of mass media exposure and extension contact. Further added that, respondents reported positive impact on BKKY and socio-economic characteristics like education, income, mass media exposure and extension contact has positive and significant association with the impact of BKKY among the farmers. Whereas, age of the respondents had negative and non-significant association with the impact of BKKY among the respondents. Meanwhile, farming experience and land holding of respondents had non-significant association with the impact of BKKY among the farmers. It was suggested to create awareness among farmers on benefits of BKKY, providing quality health consultations, proper knowledge at timely manner.

\section{REFERENCES}

[1]. Acbarya, A. (2012), "Impact of national health insurance for the poor and the informal sector in low- and middle-income countries", London: EPPICentre, Social Science Research Unit, Institute of Education, University of London, pp 8- 60, 72-105.

[2]. Bandyopadhyay, S., and Sen, K. (2017), Challenges of Rashtriya Swasthya Bima Yojana (RSBY) in West Bengal, India: An exploratory study, The International Journal of Health Planning Management, 1-15.

https:// onlinelibrary.wiley.com/doi/epdf/10.1002/hpm.2453. 


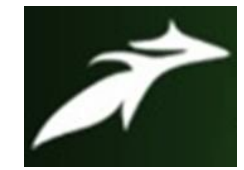

Smit Smarak Mishra et al, International Journal of Advances in Agricultural Science and Technology, Vol.8 Issue.9, September-2021, pg. 83-91

ISSN: $2348-1358$

Impact Factor: 6.057

NAAS Rating: 3.77

[3]. Gill, H., and Shahi, A. (2012). Rashtriya Swasthya Bima Yojana in Indiaimplementation, and impact. Zenith International Journal of Multidisciplinary Research, 2(5), 155-173.

[4]. Inwood, S. (2015). “Opportunities for Extension: Linking Health Insurance and Farm Viability." Journal of Extension 53(3): 3FEA1

[5]. Kiran, K. and Chetan, T. M. (2013), "Health Finance and Health Insurance in India", Indian Journal of Applied Research, Volume: 3 | Issue : 9 | Sept 2013 | ISSN - 2249555X, pp 364-367.

[6]. Nagpal, S. (2013), "Expanding Health Coverage for Vulnerable Groups in India", The World Bank, Washington DC, pp 8-15, 31-39.

[7]. Panda, B., and Rout, H. (2019), Does Public Health System Provide Adequate Financial Protection to Its Clients Through RSBY? An Exploratory Study of Tribal Odisha. Journal of Health Management, 21(4), 497-509.

[8]. Rajasekhar, D. and R, Manjula. (2012), "A Comparative Study of the Health Insurance Schemes in Kamataka", Submitted to Planning Department, Government of Karnataka, pp 1-25, 30-82, 108-200. 